\title{
IMPRESSÕES DE ESTUDANTES UNIVERSITÁRIOS SOBRE A PRESENÇA DAS MULHERES NA CIÊNCIA
}

\section{Impressions of university students about the presence of women in science}

\section{Ricardo Roberto Plaza Teixeira ${ }^{1}$}

\section{Paola Zarrella da Costa}

Resumo: O objetivo deste trabalho é analisar a presença das mulheres nas ciências naturais nos aspectos histórico, social e epistemológico e tem como objetivo esclarecer as formas como esta presença ocorre. É feita uma análise de uma pesquisa realizada com estudantes universitários de um curso de licenciatura em física sobre a relação entre as mulheres e a ciência. São analisadas, também, as estratégias e práticas pedagógicas de educação científica que melhor se adaptem ao perfil feminino para permitir que professores de ciências naturais atuem como agentes de mudanças de modo a atrair mais mulheres para este campo de conhecimento.

Palavras-chave: história da ciência; mulher; física; sexismo.

\begin{abstract}
The objective of this paper is to analyze the presence of women in natural sciences in its historical, social and epistemological aspects, with the objective of clarifying the ways in which this presence occurs. An analysis of a research carried out with university students of a course of physics about the relation between women and science is made. Some pedagogical practices and strategies of scientific education that better adapt to the women style are also analyzed in order to allow teachers of natural sciences to act as agents of change so that they can attract a greater number of women to this knowledge field.
\end{abstract}

Key-words: history of science; woman; physics; sexism.

\footnotetext{
${ }^{1}$ Doutor em Física pela USP e professor do CEFET-SP (Rua Pedro Vicente, 625 - São Paulo SP - CEP: 01109-010) e da PUC-SP (Rua Monte Alegre, 984 - São Paulo - SP - CEP: 05014001). E-mail: rrpteixeira@bol.com.br.

${ }^{2}$ Licenciada em Física pelo CEFET-SP. E-mail: papi_za@hotmail.com.
} 


\section{1- INTRODUÇÃO: MULHERES, CIÊNCIA E EDUCAÇÃO}

Durante boa parte da história da humanidade a mulher permaneceu alijada do direito ao livre pensar e as que transgrediam esta regra, muitas vezes, alcançaram a própria ruína. Aristóteles (1996), referência para todo o pensamento ocidental, afirmou: "Também como entre os sexos, o macho é por natureza superior e a fêmea inferior, o macho governa e a fêmea é sujeito". Durante a Inquisição, rotuladas de bruxas, foram banidas do convívio social e, em milhares de casos, incineradas: nessa época, os homens que realizavam investigações eram vistos como sábios, enquanto as mulheres que tivessem o mesmo espírito investigativo assim o faziam devido a alguma relação com o demônio, segundo o senso comum vigente na época (Chassot, 2003). No século XIX, ocorreram inúmeros "ataques” contra a mulher. O escritor e psicólogo Gustave Le Bon, por exemplo, escreveu em 1879: "Nas raças mais inteligentes, como é o caso dos parisienses, existe um grande número de mulheres cujo cérebro se aproxima mais em tamanho ao do gorila que ao do homem, mais desenvolvido. Essa inferioridade é tão óbvia que ninguém pode jamais contestá-la; apenas seu grau é digno de discussão. [...] Sem dúvida existem algumas mulheres que se destacam, muito superiores ao homem mediano, mas são tão excepcionais quanto o aparecimento de qualquer monstruosidade, como um gorila com duas cabeças; portanto, podemos deixá-las totalmente de lado.”

A sociedade, entretanto, evoluiu e muitas mulheres passaram a ocupar espaços de proporções inesperadas anteriormente, porém insuficientes. Passando de um dilema a outro, em função da busca de oportunidades no mercado de trabalho, ela teve de, em decorrência deste imperativo, suprimir seu "eu feminino" e permitir predominar em si o "animus" - o aspecto masculino inerente à mulher, tal como definido por Jung (1976): "A mulher é compensada por meio de uma essência masculina; por isso, seu inconsciente tem uma espécie de marca masculina”. Negligenciando sua feminilidade, é obrigada a assumir um projeto de homem em seus erros e acertos, moldando-se às exigências do sistema.

A revolução feminista, ao mesmo tempo que propiciou maior igualdade entre homens e mulheres na sociedade, em certo sentido aprisionou a mulher a dogmas com os

quais freqüentemente não se identifica. Para além de "dona de casa" e de "guerreira", 
muitas mulheres reivindicam da sociedade uma reavaliação de forma a abrigá-las na íntegra. Para toda a sociedade também a questão feminina é fundamental. Segundo J. Attali (2001), em seu Dicionário do Século XXI, “a educação das meninas terá a longo prazo um impacto muito maior que a dos meninos” visto que o bem-estar das mulheres é um fator chave para o progresso social.

Neste contexto é importante indagar como é a relação entre a ciência e as mulheres na atualidade. Uma pergunta mais provocativa seria: qual a intensidade do vínculo entre a mulher e as ciências exatas, especialmente a física e a matemática? Os dados evidenciam ainda hoje uma pequena participação feminina neste setor. Segundo pesquisas realizadas pelo American Institute of Physics (2005), está se ampliando a comunidade de pesquisadoras em áreas como a engenharia e as ciências da computação. Porém, a percentagem de mulheres pesquisadoras em física tem sido a menor registrada em todos os campos associados às ciências exatas. Muitos pesquisadores afirmam que a principal causa da pequena participação feminina na física não está fundamentalmente no fato de elas serem desencorajadas ao ingresso neste meio acadêmico. A questão fundamental é que elas são verdadeiramente expulsas quando conseguem ingressar neste meio: em cada etapa da carreira acadêmica elas são “empurradas” para longe da física (Hilborn, 2003; Whitten, 2007) com os mecanismos de ascensão na carreira funcionando como verdadeiros filtros de gênero (Blickenstaff, 2005). O estudo realizado pelo American Institute of Physics (2005) mostrou que nos Estados Unidos da América o percentual de mulheres atuando nos diferentes níveis da física diminui à medida que se avança na carreira. No ensino médio norte-americano - com as suas peculiaridades sobre disciplinas optativas que permitem aos estudantes montar parte do currículo - cerca de metade dos estudantes de física são do gênero feminino. Mas enquanto 22\% dos estudantes que se formam em um curso de bacharelado em física são mulheres, elas compõem 18\% daqueles que obtêm título de doutorado em física. Finalmente, entre os professores assistentes de física, cerca de 15\% são mulheres e entre os professores titulares de física apenas aproximadamente 5\% são mulheres. Um estudo realizado por M. E. Estébanez (2003) em países da América Latina chegou à mesma conclusão: a porcentagem de mulheres diminui significativamente nos pontos mais altos da escala acadêmica e este processo é ainda mais intenso em instituições de grande prestígio e em 
postos de alto poder de decisão na ciência. No Brasil, por exemplo, em 2000, enquanto $20 \%$ dos estudantes de física eram mulheres, elas representavam apenas $1 \%$ dos docentes de física universitários com bolsa de produtividade em pesquisa do CNPq (Conselho Nacional de Desenvolvimento Científico e Tecnológico) no nível 1A, o mais alto.

Para M. Barbercheck (2001), há dois modelos dominantes - e na verdade complementares - que explicam o motivo pelo qual as mulheres estão menos representadas em campos científicos e têm menos sucesso que os homens em carreiras científicas. O primeiro modelo é o modelo de déficit, que associa o menor número de mulheres cientistas ao tratamento diferencial dado a elas. Este modelo enfatiza as barreiras estruturais - legais, políticas e sociais - que existem ou existiram no sistema social da ciência. Um pressuposto deste modelo é o de que mulheres e homens têm objetivos similares, mas as barreiras aos avanços mantêm as mulheres distantes de atingir estes objetivos em taxas similares às dos homens. O segundo modelo, o modelo da diferença, afirma que há menos mulheres que homens na ciência porque as mulheres agem diferentemente. O modelo da diferença assume que há diferenças fundamentais entre os objetivos de homens e mulheres. Os obstáculos na carreira estão na própria mulher - eles são inatos para uns ou resultantes da socialização e de valores culturais para outros - e a ciência é assim definida como um campo masculino, desencorajando a participação feminina.

Seria uma falácia negar que não haja desinteresse por uma parcela das mulheres pela física, desinteresse este que vem diminuindo: o percentual de professoras de física e química no Brasil aumentou de 31,2\% em 1988 para 38,3\% em 1998 (Rosemberg, 2001). Porém, em contrapartida, existe um paradigma vigente em nossa sociedade que contrapõe as ciências exatas a muitas características inerentes à feminilidade. Concomitantemente, o senso comum afirma - de forma simplista - que as oportunidades estão dadas e são as mulheres que não sabem fazer bom uso delas. Por isto, é legítimo propor que esta desigualdade pode e deve ser superada. O direito à igualdade na ciência e na tecnologia precisa se traduzir como igualdade no acesso à educação, às carreiras científicas e às instâncias de decisão sobre o desenvolvimento da ciência e da tecnologia na sociedade. A própria ciência ressente-se desta situação, pois se priva de obter novas mentes e consciências que possam contribuir com olhares diferenciados sobre os fenômenos 
naturais. Além disso, um país que visa ao desenvolvimento econômico, científico e tecnológico não pode manter uma parcela tão expressiva de sua população distante de campos tão importantes do conhecimento humano.

Contudo, pesquisadores do assunto evidenciam um importante problema: não basta apenas estimular as mulheres meramente lhes oferecendo oportunidades. Isto de certo modo ocorre na atualidade e como se percebe não surtiu resultados plenamente satisfatórios. A ciência é constituída por uma estrutura sólida e hermeticamente masculina, tanto em sua epistemologia quanto em seu formato e na sua concretização na forma de “comunidade científica”. A mulher que se aventura no meio tecno-científico é compelida a transfigurar-se, adaptando-se a este universo de ethos predominantemente masculino, rejeitando, freqüentemente, neste processo sua essência mais feminina. Assim, em geral a mulher não se sente confortável neste papel: a ciência, desta forma, não se faz atraente para este universo feminino.

Sendo o professor um dos principais meios de divulgação da ciência entre os jovens, o contato direto que possui com os alunos permite trabalhar com conceitos e formar opiniões. É nesta instância da relação de ensino-aprendizagem que a figura deste profissional se torna imprescindível, pois pode redirecionar práticas e sugerir novos modelos. Potencialmente são os professores - não exclusivamente - que têm a possibilidade de dar início efetivo a uma mudança de mentalidade que permita uma inserção maior das mulheres como cidadãs interessadas no conhecimento científico. A mulher deve ser incentivada à prática científica durante a sua educação básica, com métodos pedagógicos e práticas de ensino que a motivem a interessar-se por ciência e, em especial, pela física, superando as desigualdades existentes.

Para isto concretizar-se, três frentes de pesquisa podem colaborar na elucidação dos desafios a serem vencidos: uma análise histórica, uma compreensão ampliada da epistemologia da física e um estudo dos métodos pedagógicos utilizados nos processos de educação. A analise histórica permite, por meio do levantamento de dados - inclusive estatísticos -, esclarecer a forma como se deu a evolução da presença feminina na ciência e seus “anonimatos” até a atualidade. Estas informações históricas podem ser usadas como forma de estímulo para muitas alunas do ensino médio e de cursos de ciências exatas. É útil para este objetivo - apesar de não ser condição suficiente - verificar os 
códigos morais e as estruturas econômicas de diferentes períodos históricos que no decorrer da evolução das civilizações humanas permitiram suprimir consideravelmente a presença produtiva da mulher na ciência. A análise epistemológica possibilita refletir sobre o modo feminino de pensar a ciência, em seus múltiplos aspectos, com o objetivo de diagnosticar as afinidades e os obstáculos que distanciam muitas mulheres da ciência, com isso diminuindo o abismo existente entre a mulher e a ciência. A pedagogia por fim é útil como ferramenta indispensável para uma proposta de transformação que permita maior aproximação do corpo discente feminino com a ciência. Desta forma, devem ser escolhidos métodos pedagógicos adequados para tais objetivos e que possuam coesão e conformidade com as metas definidas e os resultados desejados: práticas que produzam uma empatia feminina pela ciência.

Importantes organizações governamentais e privadas - como a “L’Oreal”, por exemplo - vêm trabalhando com as questões de gênero relacionadas à ciência e investindo grandes valores em bolsas científicas para mulheres pesquisadoras. A Unesco também vem ampliando as iniciativas que possibilitem estudos da situação da mulher na ciência por meio de postos de pesquisa em diferentes países ou de fundos específicos para estudos sobre questões de gênero.

Tais condutas são hoje mais freqüentes, pois corretamente se pressupõe que o futuro da ciência também estará cada vez mais em mãos femininas, levando-se em consideração o diagnóstico cada vez mais real de que há um paradigma emergente para o modo como a ciência se estrutura (Santos, 2000): hoje ela crescentemente adquire um caráter interdisciplinar, multifacetado e complexo (Morin, 1996), necessitando de mentes flexíveis, característica marcadamente feminina. Para M. Kaku (2001): “No passado, a abordagem reducionista foi generosamente compensadora, acabando por estabelecer os fundamentos da física, da química e da biologia modernas. [...] O século XXI, diferentemente dos anteriores será caracterizado pela sinergia [...]”. Assim sendo, a sociedade em rede permite o estabelecimento concreto de uma inteligência coletiva (Castells, 2000; Levy, 2000) que mobiliza diversas competências de modo diferente do paradigma reducionista que permitiu a consolidação da física clássica, por exemplo, no século XIX, durante o qual uma visão sexista de mundo esteve no âmago de muitos dos seus pressupostos científicos (Trecker, 2001). 
Apesar de todos os avanços das últimas décadas, a presença profissional feminina nas áreas científicas está muito aquém do desejável (Santos, 2006). Vários grupos em diferentes países do globo estão se estruturando para estudar as barreiras que impedem uma ampliação efetiva da presença das mulheres na física. A "Internacional Union of Pure and Applied Physics” (IUPAP) organizou, em 1999, o “Working Group on Women in Physics" (Grupo de Trabalho sobre Mulheres na Física) e, em 2002, realizou uma conferência internacional sobre mulheres na física na cidade de Paris (IUPAP, 2002). Os seus 300 participantes representando 65 paises tiveram a oportunidade de avaliar os problemas existentes e as propostas para ampliar a participação feminina na ciência em geral e na física em particular. Uma das suas conclusões foi que a baixa participação de mulheres na física é um fenômeno complexo e que se manifesta de diferentes formas. Dessa forma, um modo efetivo de solucionar este problema é por meio de soluções específicas para cada realidade local. Algumas das propostas incluem políticas educacionais elaboradas para salientar métodos de ensino que respeitem as diferenças de gênero e práticas que levem à superação da falta de eqüidade e de transparência nos processos de avaliação e ascensão nas carreiras científicas. A nota final da conferência afirmava que "a solução desses problemas beneficiará homens e mulheres e garantirá a sobrevivência da física”. Uma das conclusões deste trabalho é a de que o ensino médio é o melhor momento de se conquistar as mulheres para a física: uma atuação focada nesta faixa etária possibilita que não se elimine do caminho científico ninguém com potencial para essa área do conhecimento. Dessa maneira, os pesquisadores em educação que realmente considerem este um problema fundamental estão desafiados a atacar o problema do olhar tipicamente masculino nessa etapa do ensino no Brasil. Confirmando este diagnóstico, um estudo realizado em 2006 pelo American Institute of Physics-AIP com mais de 1.350 mulheres físicas de 70 países (incluindo 44 físicas brasileiras) revelou que a maioria delas escolheu a física como carreira durante o ensino secundário.

\section{2- PERCEPÇÕES DOS ESTUDANTES DE LICENCIATURA EM FÍSICA}

Com o objetivo de verificar a percepção a respeito do papel das mulheres nas ciências naturais realizamos em 2006 uma pesquisa na qual foram entrevistados 66 
estudantes de diferentes semestres do curso de licenciatura em física do CEFET-SP (Centro Federal de Educação Tecnológica de São Paulo), sendo que 21 eram mulheres e 45 eram homens. A idade média das estudantes pesquisadas foi de 23,0 anos, menor que a idade média dos estudantes do sexo masculino, que foi de 25,7 anos, corroborando uma pesquisa realizada por F. Rosemberg (2001), segundo a qual em geral nos cursos universitários brasileiros “a porcentagem de formandos no grupo etário mais jovem (até 24 anos) é maior entre as mulheres que entre os homens”.

Neste trabalho, os estudantes responderam a um questionário com perguntas relacionadas a questões sobre gênero e ciência. Na primeira pergunta foi solicitado que o estudante escrevesse o nome de até dois cientistas do sexo masculino e de até duas cientistas do sexo feminino que ele(a) conhecesse e que fossem considerados importantes no quadro mundial; em seguida, foi solicitado que o estudante escrevesse o nome de até dois cientistas brasileiros do sexo masculino e de até duas cientistas brasileiras do sexo feminino que fossem considerados importantes. A tabela 1 apresenta os nomes dos cientistas e das cientistas lembrados que tiveram mais de uma citação e as porcentagens em que eles foram citados. As porcentagens não somam 100\% porque há nomes que foram citados uma só vez e que não aparecem nesta tabela e, igualmente, porque cada estudante poderia citar até dois nomes. No que diz respeito aos cientistas homens, os três mais citados tanto por alunas quanto por alunos foram Einstein, Newton e Galileu, que foram seguidos por Kepler, Bohr, Fermi e Planck. Uma característica relevante desta tabela é que as porcentagens das citações nos casos das alunas são sistematicamente menores que no caso dos alunos, pois entre as mulheres aparece um percentual maior de respostas em branco. Foram citados também uma única vez pelos alunos os nomes de Von Braun, Sabin, Salk, Hubble, Stephen Hawking, Mendel, Thomas Edson, Maxwell, D’Alembert, Galois, Feynman, Heisenberg e Darwin. Pelas alunas, foram citados uma única vez os nomes de Bohr, Kepler, Heisenberg e Rutherford.

No que diz respeito às cientistas mulheres, há quase que uma concentração total no nome da física franco-polonesa Marie Curie - que ganhou o prêmio Nobel duas vezes no início do século XX (Santos, 1991) - com duas alunas citando também o nome de sua filha, Irène Curie, que, como a mãe, recebeu o prêmio Nobel. Foram citados também uma única vez pelos alunos os nomes das físicas nucleares Lise Meitner (que foi fundamental 
para a descoberta da fissão nuclear) e Leona Woods (que participou da construção da primeira bomba atômica durante a Segunda Guerra Mundial), bem como o nome da física Mileva Einstein, primeira esposa de Albert Einstein. As alunas lembraram também os nomes de duas francesas proeminentes: a matemática Sophie Germain e a física Marquesa Émilie du Châtelet. As porcentagens sistematicamente menores para as alunas do que para os alunos (tanto na referência aos cientistas quanto na referência às cientistas) indicam uma menor força em modelos de cientistas no caso delas. A menor diversidade de nomes lembrados de cientistas mulheres em relação à diversidade de nomes de cientistas homens lembrados indica, da mesma forma, a falta de modelos de mulheres cientistas para todos os alunos de licenciatura em física pesquisados. Não se trata de ausência de heróis - triste é um país que precisa de heróis, nas palavras de Brecht - mas de modelos profissionais bem sucedidos na área da física para estudantes de um curso de licenciatura que forma exatamente professores para lecionar a disciplina da física.

No que diz respeito aos cientistas brasileiros do sexo masculino, a grande referência para os estudantes e para as estudantes é o nome do físico César Lattes, descobridor dos mésons pi. Foram lembrados também de forma significativa os nomes do físico e divulgador da ciência Marcelo Gleiser, do inventor do avião Santos Dumont, do físico José Leite Lopes e do sanitarista Carlos Chagas. Os estudantes citaram ainda - uma única vez - os nomes do jornalista científico Pedro Neves, do astrônomo Ronaldo Rogério de Freitas Mourão, do padre Landell (um dos inventores do rádio), do médico epidemiologista Adolfo Lutz e do sanitarista Oswaldo Cruz, enquanto as estudantes citaram uma única vez o nome do físico Mário Schenberg.

Finalmente, quando foi solicitado para que fossem citados nomes de duas grandes cientistas brasileiras, um grande vazio se instalou: as estudantes de física não citaram qualquer nome, enquanto um estudante citou o nome de sua mãe - que trabalha na área científica - e outro citou o nome de uma das professoras de física de seu curso. Portanto, faltam modelos de mulheres nas ciências em geral e estes modelos são ainda mais raros no caso de cientistas brasileiras.

Isto pode também ser constatado a partir das respostas à pergunta feita no questionário sobre se o estudante sentiu dificuldades para citar nomes de cientistas 
mulheres: $100 \%$ das estudantes afirmaram ter sentido dificuldade enquanto $87 \%$ dos homens afirmaram ter tido dificuldade para citar nomes de cientistas brasileiras.

\begin{tabular}{|c|c|c|}
\hline $\begin{array}{l}\text { Nome do cientista } \\
\text { homem }\end{array}$ & $\begin{array}{c}\text { Porcentagem de citações feitas } \\
\text { pelos estudantes homens }\end{array}$ & $\begin{array}{c}\text { Porcentagem de citações feitas } \\
\text { pelas estudantes mulheres }\end{array}$ \\
\hline Einstein & $71 \%$ & $43 \%$ \\
\hline Newton & $36 \%$ & $43 \%$ \\
\hline Galileu & $20 \%$ & $10 \%$ \\
\hline Kepler & $16 \%$ & $5 \%$ \\
\hline Bohr & $11 \%$ & $5 \%$ \\
\hline Fermi & $9 \%$ & - \\
\hline Planck & $4 \%$ & - \\
\hline $\begin{array}{l}\text { Nome da cientista } \\
\text { mulher }\end{array}$ & $\begin{array}{l}\text { Porcentagem de citações feitas } \\
\text { pelos estudantes homens }\end{array}$ & $\begin{array}{c}\text { Porcentagem de citações feitas } \\
\text { pelas estudantes mulheres }\end{array}$ \\
\hline Marie Curie & $49 \%$ & $38 \%$ \\
\hline Irène Curie & - & $10 \%$ \\
\hline $\begin{array}{l}\text { Nome do cientista } \\
\text { homem brasileiro }\end{array}$ & $\begin{array}{l}\text { Porcentagem de citações feitas } \\
\text { pelos estudantes homens }\end{array}$ & $\begin{array}{c}\text { Porcentagem de citações feitas } \\
\text { pelas estudantes mulheres }\end{array}$ \\
\hline César Lattes & $38 \%$ & $24 \%$ \\
\hline Marcelo Gleiser & $11 \%$ & $14 \%$ \\
\hline Santos Dumont & $7 \%$ & $5 \%$ \\
\hline Leite Lopes & $4 \%$ & $14 \%$ \\
\hline Carlos Chagas & $4 \%$ & - \\
\hline
\end{tabular}

Na seqüência, foram feitas algumas perguntas sobre as relações entre as mulheres e as ciências naturais que tinham como respostas possíveis "sim" ou "não". Estas perguntas, bem como os percentuais de respostas "sim" dadas pelos estudantes do sexo 
masculino e pelas do sexo feminino aparecem na tabela 2: não ocorreram muitas diferenças nas respostas dos estudantes e das estudantes. A participação das mulheres na ciência é julgada importante pela maioria esmagadora dos entrevistados. Mais da metade dos entrevistados pensa que há preconceitos por parte da comunidade científica em relação às mulheres cientistas. Mais que dois terços dos entrevistados acham que homens e mulheres elaboram seus pensamentos e analisam a realidade de formas diferentes, o que não é algo necessariamente negativo, pois a diversidade de maneiras de pensar é boa para a evolução da ciência. Por outro lado, 20\% dos estudantes e 14\% das estudantes acham que existem diferenças nas capacidades intelectuais entre homens e mulheres, que é, agora sim, algo pelo menos potencialmente negativo e preocupante. Normalmente muitos assumem implicitamente que, se há diferenças entre as capacidades intelectuais médias entre homens e mulheres, é porque esta diferença deve ser contra as mulheres de modo que as suas capacidades devam ser menores, mas na pergunta nada indica este viés e pode-se igualmente pensar que alguns - ou algumas - estudantes dentre aqueles que responderam “sim” a esta resposta assumiram um viés contrário às capacidades cognitivas masculinas!

Tabela 2 - Porcentagens de respostas dos estudantes e das estudantes do curso de licenciatura em Física do CEFET-SP à questões relacionadas ao papel das mulheres nas ciências

\begin{tabular}{|l|c|c|}
\hline Perguntas & $\begin{array}{l}\text { Percentual de respostas } \\
\text { “sim” entre estudantes } \\
\text { do sexo masculino }\end{array}$ & $\begin{array}{l}\text { Percentual de respostas } \\
\text { “sim” entre estudantes do } \\
\text { sexo feminino }\end{array}$ \\
\hline $\begin{array}{l}\text { 1-Você julga importante e produtiva a participação feminina na } \\
\text { ciência? }\end{array}$ & $96 \%$ \\
\hline $\begin{array}{l}\text { 2- Na atualidade você acredita que exista preconceito por parte } \\
\text { da comunidade científica em relação às mulheres cientistas? }\end{array}$ & $58 \%$ & $67 \%$ \\
\hline $\begin{array}{l}\text { 3- Na sua opinião, homens e mulheres elaboram seus } \\
\text { pensamentos e analisam a realidade de maneiras diferentes? }\end{array}$ & $73 \%$ & $14 \%$ \\
\hline $\begin{array}{l}\text { 4- Na sua opinião existem diferenças entre homens e mulheres } \\
\text { no que se refere à capacidade intelectual? }\end{array}$ & $20 \%$ & $67 \%$ \\
\hline
\end{tabular}

Em seguida, uma pergunta de caráter subjetivo tentou aprofundar a análise de como os estudantes sentem o modo pelo qual a ciência realmente trabalha: "Você acredita que a ciência 'pensa' como se fosse um homem ou uma mulher?” Claramente a 
pergunta procura aferir como a ciência ocorre cotidianamente: se por um lado a ciência não é uma pessoa que pode pensar, por outro lado o fazer científico é no mundo todo realizado por milhões de homens e mulheres que pensam de formas específicas (Schienbinger, 2001). Apesar disto, pode ter existido uma incompreensão quanto a esta pergunta, pois tanto para os estudantes quanto para as estudantes existiu um percentual grande de $47 \%$ de entrevistados que simplesmente não responderam esta pergunta. Entre os estudantes / as estudantes de licenciatura em física, um percentual de 40\% / 38\% respondeu que a ciência 'pensa' como homem, enquanto 7\% / 9\% responderam que a ciência 'pensa' como mulher.

Há um velho debate constante sobre o caráter das diferenças de aptidões e de habilidades entre homens e mulheres: determinismo biológico versus determinismo ambiental (Moro, 2001). Para sondar a forma pelas quais os estudantes "percebem” este debate, foi perguntado aos entrevistados sobre se as diferenças de desempenho entre homens e mulheres nas ciências exatas devem-se mais a fatores genéticos ou a fatores culturais: uma maioria de $62 \%$ dos estudantes e de $67 \%$ das estudantes respondeu que estas diferenças devem-se mais a fatores culturais, enquanto os que defenderam que a genética é a principal causa disto foram $7 \%$ entre os estudantes e 14\% entre as estudantes, sendo que o restante atribuiu estas diferenças de desempenho a outros fatores.

Foram feitas então quatro perguntas a respeito das formas pelas quais os estudantes preferem aprender nas disciplinas científicas. A primeira destas perguntas foi: "Você prefere aprender em um ambiente cooperativo e solidário ou em um ambiente que estimule a competitividade?”. Entre as estudantes, $76 \%$ preferem um ambiente cooperativo contra $10 \%$ que preferem um ambiente competitivo. Já entre os homens, uma maioria de 73\% também diz preferir ambientes de aprendizagem cooperativos, mas significativos $24 \%$ deles - cerca de um quarto - preferem ambientes competitivos: homens são mais competitivos no processo de aprendizagem ou, pelo menos, alguns homens assim se comportam. A propósito, na análise das respostas dadas, sempre devemos considerar a possibilidade de que muitos dos entrevistados possam estar respondendo não àquilo que pensam, mas sim àquilo que achem adequado no momento, ou seja, àquilo que considerem politicamente correto - mesmo sabendo que nenhum dos entrevistados se identificava na folha de reposta ao questionário. 
A segunda destas perguntas foi: "Você prefere estudar normalmente só ou em grupo?” Entre os estudantes do sexo masculino, 58\% responderam que preferem estudar sozinhos contra 36\% que responderam preferir estudar em grupo. Entre as estudantes de física, ocorreu uma inversão, pois existiu uma maior porcentagem (48\%) daquelas que preferem estudar em grupo em relação a $43 \%$ daquelas estudantes que preferem estudar solitariamente.

A terceira destas perguntas foi: "Quando você estuda física, você prefere aprender: primeiro o conceito físico e depois o formalismo matemático aplicado à física ou primeiro o formalismo matemático aplicado à física e depois o conceito físico?” Esta pergunta é importante, pois permite refletir de maneira mais aprofundada sobre o papel da matemática no ensino da física em geral, uma questão que vem sistematicamente preocupando a comunidade de pesquisadores de ensino de física. Dentre as estudantes do curso de licenciatura em física, $85 \%$ delas preferem aprender primeiro o conceito físico contra 5\% daquelas que preferem aprender primeiro o formalismo matemático. Já entre os estudantes, uma maioria de 73\% também prefere aprender primeiro o conceito físico, mas há novamente significativos 27\% (mais uma vez cerca de um quarto) dos estudantes que preferem aprender primeiro o formalismo matemático aplicado à física e só depois o conceito físico. Pode-se objetar que a questão é vaga e subjetiva, mas os resultados obtidos mostram que pelo menos uma parte dos estudantes homens apresenta uma visão a respeito da aprendizagem da física que é significativamente diferente daquela da esmagadora maioria das estudantes.

A quarta destas perguntas foi: "Você prefere aprender: predominantemente a teoria do fenômeno em detrimento da experimentação ou tendo a experimentação como eixo principal para a compreensão do fenômeno?” Aqui as respostas não se apresentaram muito diferentes, pois dentre os estudantes homens uma maioria de $67 \%$ prefere aprender física tendo a experimentação como eixo principal contra 29\% que preferem que a ênfase esteja na teoria do fenômeno, enquanto entre as estudantes há também uma maioria de $62 \%$ que prefere aprender física a partir preferencialmente da experimentação contra $28 \%$ das estudantes que preferem uma ênfase maior na teoria.

O interesse de um aluno por fazer um curso na área das ciências naturais, como é o curso de licenciatura em física, muitas vezes advém de algum modelo positivo - na sua 
infância ou adolescência - de uma pessoa ligada à área científica: um professor, um parente (tio, tia, avô, avó etc), uma personalidade pública (geralmente um cientista), ou mesmo o pai ou a mãe. Por isso é interessante conhecer como é o nível de escolaridade do pai e da mãe das alunas e dos alunos de licenciatura em física pesquisados. A tabela 3 apresenta os resultados em termos de 4 níveis de escolaridade: fundamental (antigo $1^{0}$ grau), médio (antigo $2^{\circ}$ grau), superior e pós-graduação (novamente, existiram respostas em branco e, por isso, as porcentagens não somam 100\%).

\begin{tabular}{|c|c|c|c|c|}
\hline \multicolumn{5}{|c|}{ Tabela 3 - Nível de escolaridade dos pais dos alunos pesquisados } \\
\hline Escolaridade & Fundamental & Médio & Superior & Pós-graduação \\
\hline Pai da aluna & $38 \%$ & $38 \%$ & $19 \%$ & - \\
\hline Mãe da aluna & $29 \%$ & $48 \%$ & $10 \%$ & $5 \%$ \\
\hline Pai do aluno & $36 \%$ & $40 \%$ & $22 \%$ & $2 \%$ \\
\hline Mãe do aluno & $33 \%$ & $47 \%$ & $18 \%$ & - \\
\hline
\end{tabular}

É possível notar que nos quatro casos o mais freqüente é que a escolaridade do genitor seja a equivalente ao ensino médio, apesar de ser possível notar que tanto para as alunas quanto para os alunos: 1) há mais pais do que mães somente com o ensino fundamental; 2) há mais pais do que mães com o ensino superior. Portanto, se pudéssemos mensurar o nível de escolaridade pelo número de anos de escolaridade de cada genitor, o desvio padrão e a dispersão deste número de anos de escolaridade seria maior no caso dos pais que no caso das mães. A menor porcentagem nos quatro casos analisados com nível superior de escolaridade ocorre para a mãe das alunas (10\%) e a maior porcentagem ocorre para o pai dos alunos (22\%).

Uma questão fundamental - não abordada por este trabalho - envolve tentar descobrir quem influenciou os alunos em geral (e principalmente as alunas) para que fizessem a opção por esta área de estudo. De qualquer forma, parece claro que em uma situação em que há poucas cientistas naturais, as meninas na infância e na adolescência terão menor probabilidade de encarar as ciências naturais como um meio de vida para elas no futuro (Spelke, 2005). 


\section{3- CONCLUSÕES}

A ciência é um empreendimento humano e, portanto, deve servir às mulheres tanto quanto aos homens: superar práticas sexistas na ciência é condição necessária para um mundo emancipado (Sayers, 1989). Neste trabalho, procuramos ressaltar a relevância com que devem ser investigadas as questões de gênero relacionadas à educação científica. A questão fundamental identificada é como superar as desigualdades e ao mesmo tempo respeitar as diferenças, as peculiaridades e a diversidade. De acordo com Boaventura de Souza Santos (2002): "Temos direito à igualdade sempre que a diferença nos inferioriza. Temos direito à diferença sempre que a igualdade nos descaracteriza." Pelas percepções de alunos e alunas de um curso de licenciatura em física e, portanto, de futuros professores de física, fica claro que é fundamental que o educador em geral leve em conta as diferenças individuais nas percepções a respeito da ciência de seus alunos e de suas alunas no seu trabalho pedagógico. As pessoas individualmente são diferentes e tratá-las uniformemente não colabora para que todas compreendam os conceitos científicos que devem ser aprendidos durante as aulas. As diferentes formas de percepção dos seres humanos condicionam as diferentes maneiras de aprender de cada um: desconsiderar este fato constitui um erro crasso que pode freqüentemente afastar muitas jovens de carreiras científicas e pode também contribuir para um aumento na evasão das alunas dos cursos superiores de ciências naturais.

Por outro lado, não se pode perder de vista que muitos "fatos" sociais e comportamentais sobre as diferenças entre homens e mulheres na sociedade são naturalizados pelo senso comum como manifestações de diferenças sexuais exclusivamente biológicas e genéticas (Lewontin, 1984), desprezando-se a cultura e os fatores ambientais, algo bastante conveniente do ponto de vista masculino, já que implica uma divisão social de trabalho imutável entre os sexos. Na verdade, os papéis atribuídos a homens e a mulheres variam dependendo da cultura e da sociedade em que as pessoas estão inseridas (Casagrande, 2006). Homens e mulheres foram e são majoritariamente ensinados a enxergar as ciências naturais de maneira distinta e os educadores têm de ter isto em mente para evitar um aumento ainda maior do preconceito. 
Um problema importante a ser enfrentado na educação científica dos jovens e das jovens deriva do fato de que há uma ausência de modelos de mulheres cientistas no mundo em geral e no Brasil em particular. Como foi apresentado antes, significativamente, quando se pede para que alguém cite o nome de uma grande mulher cientista a resposta é quase sempre o nome de Marie Curie! Se a esta pessoa se solicita um segundo nome, na maioria das vezes não se consegue resposta! Quando se solicita o nome de uma mulher cientista brasileira, a ausência de nomes e de referências é quase total. A Sociedade Brasileira para o Progresso da Ciência - a maior organização que congrega cientistas no Brasil - tem uma importante publicação denominada "Cientistas do Brasil - Depoimentos” (Candotti, 1998); nela há o depoimento de 61 grandes personalidades das ciências em geral (tanto as naturais quanto as humanas), das quais 8 (13\%) são mulheres; seus nomes e suas áreas de atuação aparecem a seguir: Johanna Döbereiner (agricultura); Maria da Conceição Tavares (economia); Maria von Paumgartten Deane (parasitologia); Nise da Silveira (psiquiatria); Marta Vanucci (biologia/oceanografia); Carmen Portinho (engenharia civil); Graziela Maciel Barroso (biologia/botânica); Carolina Bori (Psicologia). Em apenas um destes casos - Carmen Portinho - a entrevistada é de uma área das ciências exatas e mesmo no caso dela percebe-se em sua vida profissional uma grande interface com as humanidades, pois ela foi diretora por 15 anos do MAM (Museu de Arte Moderna) do Rio de Janeiro. Os modelos positivos de cientistas vão surgir paulatinamente conforme os obstáculos caiam e a presença das mulheres nas ciências aumente. Enquanto isso, é importante que os educadores preocupados com a ampliação das oportunidades e a superação das desigualdades levem em consideração em seu trabalho docente as questões de gênero e as formas pelas quais as diferentes percepções dos dois sexos a respeito da ciência podem contribuir para atrair o interesse feminino para assuntos científicos. Com a ciência cada vez mais tornando-se um empreendimento coletivo, interdisciplinar e em rede, não são somente as mulheres que ganharão com isto, mas também a própria ciência.

\section{BIBLIOGRAFIA}


AIP - AMERICAN INSTITUTE OF PHYSICS. Women in Physics and Astronomy 2005. AIP Report Number R-441, 2005.

AIP - AMERICAN INSTITUTE OF PHYSICS. Women physicists speak again. AIP Report Number R-441, 2006.

ARISTÓTELES. A política. Rio de Janeiro: Ediouro, 1996.

ATTALI, J. Dicionário do século XXI. Rio de Janeiro: Record, 2001.

BARBERCHECK, M. Mixed Messages - Men and women in advertisements in science. In: Woman, science and technology. Org: WYER, Mary. New York: Routledge, 2001.

BLICKENSTAFF, J. C. Women and science careers: leaky pipeline or gender filter? In: Gender and education. V. 17, n. 4, p. 369, 2005.

CANDOTTI, E. Cientistas do Brasil - Depoimentos. São Paulo: SPBC, 1998.

CASAGRANDE, L. S. e CARVALHO, M. G. Educando as novas gerações: representações de gênero nos livros didáticos de matemática. Caxambu: Anais da $29^{\text {a }}$ Reunião Anual da ANPED, 2006.

CASTELLS, M. A sociedade em rede. São Paulo: Paz e Terra, 2000.

CHASSOT, A. A ciência é masculina? São Leopoldo: Editora Unisinos, 2003.

ESTÉBANEZ, M. E. As mulheres na ciência regional. In: ComCiência - Revista Eletrônica de Jornalismo Científico. Laboratório de Jornalismo da Unicamp e da SBPC, n. 50, dez/2003 - jan/2004.

HILBORN, R. C. et al. What works for women in undergraduate physics? In: Physics Today. V. 56, n. 9, p. 46, 2003.

IUPAP - INTERNACIONAL UNION OF PURE AND APPLIED PHYSICS. Women in Physics: The IUPAP International Conference on Women in Physics. Paris: AIP Conference Proceedings 628, 2002.

JUNG, C. G. Os arquétipos e o inconsciente coletivo. Petrópolis: Vozes, 1976.

KAKU, Michio. Visões do futuro. Rio de Janeiro: Rocco, 2001.

LE BON, G. Recherches anatomiques et mathématiques sur les lois des variations du volume du cerveau et sur leurs relations avec l'intelligence. In: Revue d'Anthropologie: $2^{\text {a }}$ série, v. 2, 1879.

LEVY, P. Cibercultura. Rio de Janeiro: Editora 34, 2000. 
LEWONTIN, R. C., ROSE, S e KAMIN, L. J. Not in our genes. New York: Pantheon Books, 1984.

MORIN, E. Ciência com consciência. Rio de Janeiro: Bertrand Brasil, 1996.

MORO, C. C. A questão de gênero no ensino de ciências. Chapecó: Argos, 2001.

ROSEMBERG, F. Educação formal, mulher e gênero no Brasil contemporâneo. In: Revista de Estudos Feministas. Florianópolis: v. 9, n² 2, 2001.

SANTOS, A. N. M., BENTO, M. A. e AURETTA, C. Mulheres na ciência. Lisboa: Gradiva, 1991.

SANTOS, B. S. A crítica da razão indolente: contra o desperdício da experiência. São Paulo: Cortez, 2000.

SANTOS, B. S. A globalização e as ciências sociais. São Paulo: Cortez, 2002.

SANTOS, L. W., ICHIKAWA, E. Y. e CARGANO, D. F. Ciência, tecnologia e gênero. Londrina: IAPAR, 2006.

SAYERS, J. Feminismo e ciência. In: ROSE, E. e APPIGNANESI, L. Para uma nova ciência. Lisboa: Gradiva, 1989.

SCHIENBINGER, L. O feminismo mudou a ciência? Bauru: EDUSC, 2001.

SPELKE, E. The science of gender and science - Pinker vs. Spelker - A debate 16/5/2005. Disponível em: http://www.edge.org. Acessado em 3/4/2008.

TRECKER, J. L. Sex, science and education. In: Woman, science and technology. Org: WYER, Mary. New York: Routledge, 2001.

WHITTEN, B. L. et al. What works for women in undergraduate physics and what we can learn from women's colleges. In: Journal of women and minorities in science and engineering. V. 13, n. 1, p. 37, 2007. 